\title{
ARBORIZAÇÃO DA AVENIDA JERÔNIMO ROSADO NO MUNICÍPIO DE BARAÚNA - RN, BRASIL
}

\author{
TREE PLANTING ON JÊRONIMO ROSADO AVENUE IN BARAÚNA MUNICIPALITY - \\ $R N, B R A Z I L$
}

\author{
Marina Beatriz da Silva Bezerra ${ }^{1}$, Vinicius Castro², Rejane Tavares Botrel ${ }^{3}$
}

\section{RESUMO}

O objetivo deste trabalho foi realizar uma avaliação quali-quantitativa da arborização da principal avenida de Baraúna, município de pequeno porte localizado na mesorregião do oeste do Rio Grande do Norte, inserido no bioma caatinga. Para a coleta dos dados foram percorridos aproximadamente $1,7 \mathrm{~km}$, entre os meses de agosto e novembro de 2016. Na via analisada, foram encontrados 408 indivíduos arbóreos, dentre os quais houve a predominância de espécies exóticas (87,5\%), sendo Azadirachta indica A. Juss. $(68,4 \%)$ e Ficus benjamina L. $(13,2 \%)$ as espécies mais frequentes. Dentre as espécies nativas do bioma caatinga a mais abundante foi Handroanthus caraiba (Mart.) Matto (1,7\%). Observou-se a ocorrência de problemas de caráter cultural relacionados ao manejo da arborização, como poda topiaria em $64,8 \%$ dos indivíduos, bem como a prática excessiva de caiação, em $96,9 \%$ dos indivíduos. Recomenda-se a realização de trabalhos de educação ambiental junto à população voltados para a conscientização da importância do uso de espécies nativas no ambiente urbano, assim como do estresse causado às árvores por práticas de poda topiária e caiação.

Palavras-chave: Arborização urbana; Tipos de poda; Avaliação quali-quantitativa.

\section{ABSTRACT}

The aim of this work was the quantitative and qualitative evaluation of tree planting on the main avenue of Baraúna, small town located at west midland region of Rio Grande do Norte, insert in the caatinga biome. The data were collected between August and November, 2016, and it was covered approximately $1,7 \mathrm{~km}$ of extension. In this public path, a population of 408 trees was sampled, and showed a predominance of exotic species planted (87.5\%), being Azadirachta indica A. Juss. (68.4\%) and Ficus benjamina L. $(13.2 \%)$ the most frequent species. Among native species of caatinga biome, the most abundant was Handroanthus caraiba (Mart.) Matto (1.7\%). It could be notice the presence of management problems related to cultural aspect, as topiary applied in $64.8 \%$ of the trees, just as an excessive whitewashing (96.9\%). It is recommended the development of environmental education programs aiming the awareness of using native species in urban forest, as well as the stress caused to the trees by topiary and whitewashing practices.

Keywords: Urban forestry; Pruning; Quali-quantitative evaluation.

Recebido em 07.12.2016 e aceito em 20.02.2016

1 Graduanda em Engenharia Florestal, Universidade Federal Rural do Semiárido. Mossoró/RN Email: marina.bea.triz@hotmail.com

2 Engenheiro Florestal, Dr. Professor do Centro de Ciências Agrárias da Universidade Federal Rural do Semiárido. Mossoró/RN Email: vinicius.castro@ufersa.edu.br

3 Engenheira Florestal, Dra. Professora do Centro de Ciências Agrárias da Universidade Federal Rural do Semiárido. Mossoró/RN Email: rtbotrel@ufersa.edu.br 


\section{INTRODUÇÃO}

No Brasil, a apropriação do meio natural pelo crescimento das cidades ocorre de forma silenciosa e gradual, de forma a tornar o meio urbano um ambiente desconfortável para os habitantes. Este processo contribui para o aumento da poluição sonora, visual, do ar, das águas, do solo e, por isso, deve-se sensibilizar a população com relação à importância de se amenizar este quadro, que pode ser alcançado com a arborização de vias públicas, a qual é fundamental para a melhoria da qualidade de vida do ser humano nas cidades (MICHALKA JR.; MALAGUTI, 2015).

Além disso, o uso de espaços urbanísticos e aspectos de sua arborização podem proporcionar a convivência dos valores históricos e culturais de uma sociedade. Embora muitas vezes o resgate desta memória possa esbarrar no desinteresse de seus usuários, sendo importante sua preservação, e até reconstrução, sob pena de negar esse direito às gerações futuras (MELO; ROMANINI, 2008). Paula et al. (2011) contextualizaram tais preocupações também no ambiente da caatinga, utilizando como exemplo a praça Euclides da Cunha, em Recife, projetada por Burle Marx. Este renomado paisagista elaborou um jardim moderno que se constituiu um espaço favorável ao florescimento de espécies de clima árido em um ambiente úmido em 1935. Porém, com o passar do tempo, o jardim foi se descaracterizando devido à falta de conservação e a intervenção negativa da população, que desconhece o valor histórico, botânico e cultural do ambiente. Em 2003, foram realizadas ações de restauração do referido jardim. Contudo ainda faz-se necessário sensibilizar a população e órgãos públicos sobre a importância do local.

A amenização da temperatura proporcionada pela arborização urbana é um dos benefícios que merecem destaque em regiões de clima semiárido. Além disso, o sombreamento, o aumento da umidade do ar e a redução da velocidade do vento provocados pela presença de árvores também contribuem para melhorar o conforto térmico da população no meio urbano, os quais podem se refletir em diminuição do consumo de energia elétrica com o uso de aparelhos de ar condicionado.

Simpson (1998) constatou que a arborização da cidade californiana de Sacramento, EUA, que é uma região caracterizada por verões secos e quentes, foi responsável pela economia de $12 \%$ do gasto com ar condicionado, que é responsável por $1,5 \%$ do consumo total de energia elétrica do referido município. Os benefícios da arborização urbana também foram comprovados na região árida de Israel, por Shashua-Bar e Hoffman (2000). Tais autores observaram uma queda média de $2,8^{\circ} \mathrm{C}$ na temperatura, em ruas arborizadas de Tel-Aviv, onde as temperaturas médias atingem $32,7^{\circ} \mathrm{C}$, às 15 horas. 
Baraúna é um município de pequeno porte no oeste do Rio Grande do Norte, com uma população estimada para 28 mil habitantes (IBGE, 2016) e que está inserido integralmente no bioma caatinga. Além disto, parte do Parque Nacional de Furna Feia encontra-se dentro dos limites do município. No entanto, da mesma maneira que o observado para a maioria das pequenas cidades da região, Baraúna não contempla o planejamento da arborização urbana. Diante deste contexto, o presente trabalho objetivou a realização de avaliação qualiquantitativa da arborização viária da principal avenida de Baraúna, de modo a se identificar as principais espécies plantadas, assim como verificar a adequação das práticas de manejo empregadas.

\section{MATERIAL E MÉTODOS}

A área de estudo localiza-se em Baraúna, município da microrregião de Mossoró, Rio Grande do Norte. Foram coletados dados dos indivíduos arbóreos presentes no canteiro central e ao longo da Av. Jerônimo Rosado, a principal avenida que cruza a cidade com 1,67 $\mathrm{km}$ de extensão (Figura 1). A área escolhida é visivelmente a via mais arborizada do município, sendo a continuação da rodovia RN-015. De acordo com a classificação de Köppen, o clima predominante na região é do tipo BSw'h', ou seja, semiárido, que é caracterizado por temperaturas elevadas e baixas precipitações médias anuais com má distribuição das chuvas. A região está inserida no bioma caatinga.

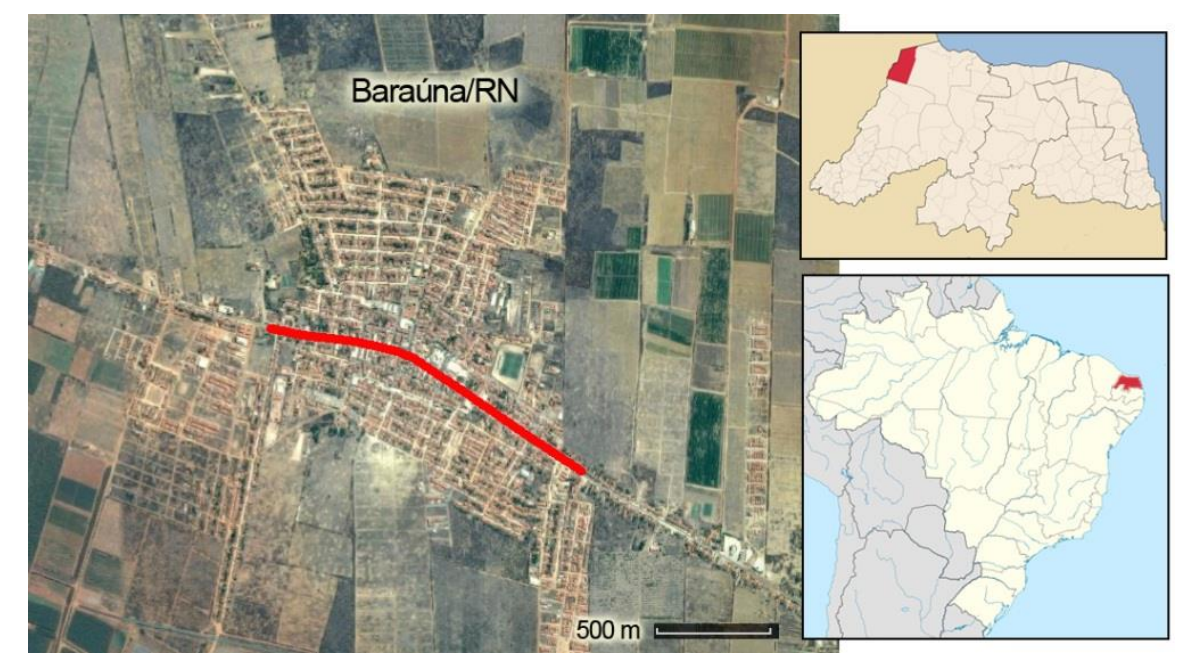

Figura 1. Imagem de satélite do município de Baraúna/RN com linha contínua representado a Avenida Jerônimo Rosado

Figure 1. Satellite image of the municipality of Baraúna / RN with the continuous line representing Jerônimo Rosado Avenue 
As árvores foram identificadas individualmente, com base nos caracteres dendrológicos e confirmação por meio de consulta na literatura, sob caráter quali-quantitativo, do tipo censo. Os dados foram coletados no período de agosto a novembro de 2016, em formulários específicos previamente elaborados com as seguintes informações: família botânica; nomes científico e popular da espécie; categoria de procedência (exótica a biomas brasileiros, exótica ao bioma caatinga ou nativa do bioma caatinga) utilizando informações de Santos, Lisboa e Carvalho (2012) e Lucena et al, (2015); condição de poda (regular, em forma V, em forma L, topiária ou drástica); condição do tronco (caiação, bifurcação abaixo de 1,8 $\mathrm{m}$ de altura ou inclinação intensiva do caule); presença de raiz aparente; danos na calçada gerados por raiz de crescimento agressivo; e disponibilidade de solo exposto ao redor da base da árvore.

A frequência relativa (\%) de cada espécie e a ocorrência dos eventuais problemas de manejo foram calculadas através da razão entre a frequência absoluta (valor observado na comunidade arbórea no estudo) e o número total de indivíduos arbóreos presentes na avenida. Os problemas encontrados na arborização foram analisados através do diagrama de Pareto, que é um gráfico de barras no qual são ordenadas as frequências das ocorrências, da maior para a menor.

\section{RESULTADOS E DISCUSSÃO}

$\mathrm{Na}$ área de estudo, foram observados 408 indivíduos pertencentes a 16 espécies e 8 famílias botânicas (Tabela 1). Além destes, também foram observados ainda quatro indivíduos da família Arecaceae uma indivíduo arbustivo da família Nyctaginaceae e cinco indivíduos que não puderam ser identificados por estarem mortos.

As espécies arbóreas de maior frequência relativa foram as espécies exóticas a biomas brasileiros Azadirachta indica e Ficus benjamina, que juntas foram representadas por aproximadamente $81 \%$ de todos os indivíduos observados. O uso abundante destas espécies na arborização urbana também foi observado em outras cidades nordestinas. Calixto Júnior, Santana e Lira Filho (2009) verificaram que estas mesmas duas espécies representaram 66\% dos indivíduos empregados na arborização da cidade de Lavras da Mangabeira, CE. Azadirachta indica foi a espécie com maior número de indivíduos na arborização do município de Timon, MA (MORAES; MACHADO, 2014). Em Fortaleza, CE, Ficus benjamina foi a espécie mais frequente na arborização urbana (45,98 \%) seguido da Azadirachta indica (7,76\%), em dois dois bairros analisados por Moro e Westerkamp (2011). 
Tabela 1. Lista das espécies registradas na arborização da avenida principal de Baraúna, RN, em 2016 Table 1. List of species registered in the afforestation of the main avenue of Baraúna, $\mathrm{RN}$, in 2016

\begin{tabular}{|c|c|c|c|c|}
\hline Nome científico & Família & $\begin{array}{c}\text { Nome } \\
\text { popular }\end{array}$ & Procedência & $\begin{array}{l}\text { FR } \\
(\%)\end{array}$ \\
\hline Azadirachta indica A. Juss. & Meliaceae & $\mathrm{Nim}$ & E-BR & 68,4 \\
\hline Ficus benjamina L. & Moraceae & Figueira & E-BR & 13,2 \\
\hline Senna multijuga (Rich.) H.S. Irwin \& Barneby & Fabaceae & Cassia & $\mathrm{E}-\mathrm{C}$ & 7,6 \\
\hline Terminalia catappa L. & Combretaceae & Castanhola & E-BR & 2,0 \\
\hline Pithecellobium dulce (Roxb.) Benth. & Fabaceae & Espinheiro & E-BR & 2,0 \\
\hline Handroanthus caraiba (Mart.) Mattos & Bignoniaceae & Craibeira & $\mathrm{N}$ & 1,7 \\
\hline Mangifera indica L. & Anacardiaceae & Mangueira & E-BR & 1,2 \\
\hline Anadenanthera colubrina (Vell.) Brenan & Fabaceae & Angico & $\mathrm{N}$ & 1,2 \\
\hline Alchornea sp. & Euphorbiaceae & Algodoeiro & $\mathrm{E}-\mathrm{C}$ & 0,7 \\
\hline Syzygium cumini (L.) Skeels & Myrtaceae & Azeitona & $\mathrm{E}-\mathrm{C}$ & 0,5 \\
\hline Tamarindus indica $L$. & Fabaceae & Tamarina & E-BR & 0,2 \\
\hline Libidibia ferrea (Mart. ex Tul.) L.P. Queiroz & Fabaceae & Jucá & $\mathrm{N}$ & 0,2 \\
\hline Prosopis juliflora (Sw.) DC. & Fabaceae & Algaroba & E-BR & 0,2 \\
\hline Delonix regia (Bojer ex Hook.) Raf. & Fabaceae & Flamboyant & E-BR & 0,2 \\
\hline Handroanthus sp. & Bignoniaceae & Ipê & $\mathrm{E}-\mathrm{C}$ & 0,2 \\
\hline Spondias purpurea L. & Anacardiaceae & Seriguela & $\mathrm{N}$ & 0,2 \\
\hline
\end{tabular}

Sendo: FR, frequência relativa; E-BR, espécie exótica a biomas brasileiros; E-C, espécie exótica ao bioma Caatinga; $\mathrm{N}$, espécie nativa do bioma Caatinga;

Redin et al. (2010) recomendam que a frequência de uma única espécie não ultrapasse $15 \%$ do total de espécies na arborização de uma área por questões estéticas e fitossanitárias. De acordo com os autores, valores acima desse percentual podem ocasionar declínio populacional devido à maior incidência de ataques de pragas ou doenças.

A utilização de indivíduos das espécies Azadirachta indica e Ficus benjamina na arborização deve ser evitada. Isto porque tais espécies são potenciais causadoras de prejuízos à infraestrutura das cidades, devido à presença de sistema radicular que aflora à superfície do solo, o porte elevado e pouco apropriado para espaços restritos ou sob fiação aérea, bem como à presença de fitopatógenos específicos (SILVA, 2012). Porém, o uso destas espécies tornou-se popular na região semiárida devido às características de rápido crescimento e resistência a condições adversas de solo e clima.

Ficus benjamina é uma espécie comumente empregada na arborização viária em diferentes estados brasileiros, conforme observado em São Paulo (CAICHE et al. 2016), Minas Gerais (OLIVEIRA et al., 2015), Paraná (HOPPEN et al., 2014) e Goiás (BARROS; GUILHERME; CARVALHO, 2010). Por outro lado, em nenhum dos trabalhos anteriormente citados verificou-se o emprego de Azadirachta indica na arborização urbana.

Dentre as espécies nativas, a espécie mais observada foi Senna multijuga (7,6\%). Contudo esta espécie foi encontrada apenas em frente às residências mais antigas presentes 
ao longo da avenida estudada. Acredita-se que isto foi reflexo do corte e substituição dos indivíduos desta espécie pelos novos moradores da região, visto que Senna multijuga frequentemente atrai o percevejo popularmente conhecido como fede-fede, que causa desconforto por produzir odor desagradável. As demais 13 espécies foram representadas por apenas $11 \%$ dos indivíduos arbóreos observados.

A espécie nativa do bioma caatinga mais encontrada foi Handroanthus caraiba $(1,7 \%)$. Esta espécie apresenta grande potencial para utilização na arborização de cidades nordestinas, devido à economia no processo de implementação do projeto, uma vez que, por ser adaptada ao clima do semiárido, a irrigação faz-se necessária apenas na estação estival dos dois primeiros anos após plantio. Além disso, possui reconhecido valor paisagístico proveniente do tamanho de sua copa e encanto de flores de tons amarelo (MEDEIROS, 2013).

No geral, o uso de espécies exóticas ao bioma caatinga foi representado por $87,5 \%$ de todos os indivíduos utilizados na arborização da área amostrada (Figura 2). Uma arborização planejada com espécies nativas da caatinga, além de mais econômica e ecologicamente correta, poderia despertar uma questão simbólica, de orgulho de sua terra e de suas origens culturais para o povo nordestino. O mais importante paisagista brasileiro Burle Marx (1987) afirmou outrora que sua obra pretendia "formar um vocabulário partindo da riquíssima flora brasileira, de sua infinita variedade, introduzindo no jardim espécies nativas, estudando, apaixonada e constantemente, as associações ecológicas, observando a paisagem natural e lutando pela preservação dessa herança". Nesse tocante podemos ainda dizer que a Caatinga, embora represente uma das biodiversidades mais ricas do Brasil, ainda é pouco estudada e aproveitada sob o ponto de vista de seu potencial ornamental. De acordo com Alvarez e Kill (2014), o uso inovador das espécies nativas da caatinga para a arborização urbana poderia ainda ser uma alternativa de renda para a população do semiárido.

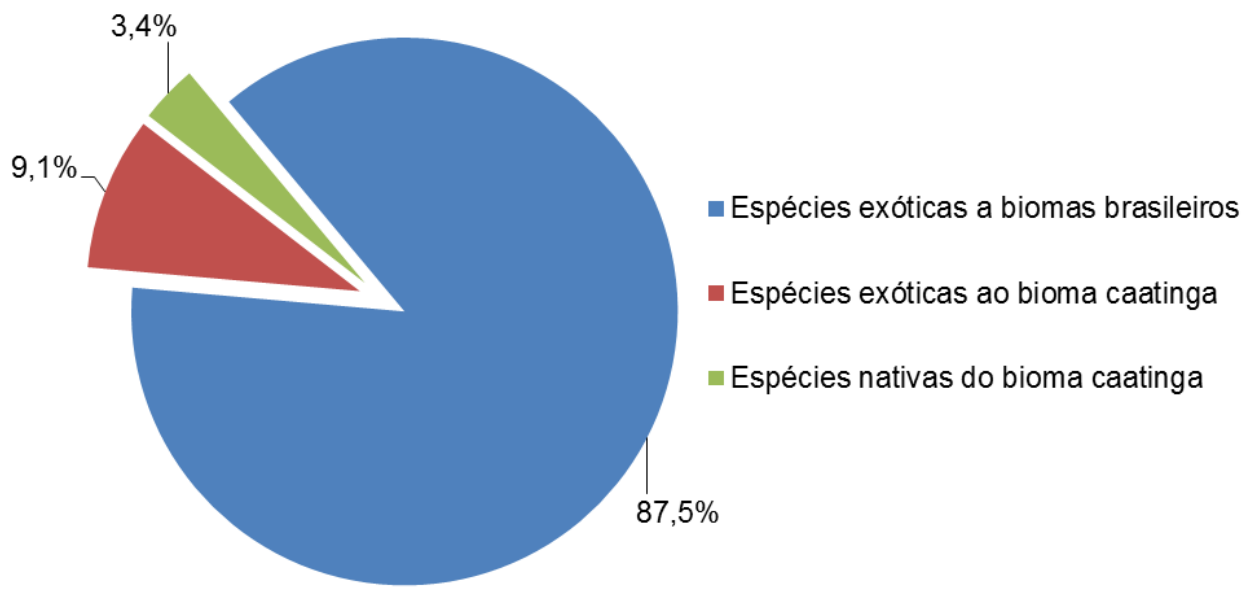

Figura 2. Porcentagem de espécies utilizadas na arborização urbana de Baraúna, RN, de acordo com a procedência

Figure 2. Percentage of species used in the urban afforestation of Baraúna, RN, according to the origin 
De acordo com a Figura 3, pode-se observar que a maior percentagem de problemas encontrados na arborização de Baraúna foi a presença de caiação nos troncos, que foi verificada em quase todos os indivíduos avaliados (96,92\%). Na sequência, os seguintes problemas foram considerados críticos, em ordem decrescente de frequência: poda em topiária (64,83\%), árvores bifurcadas abaixo de $1,8 \mathrm{~m}(46,74 \%)$ e indisponibilidade de área livre permeável na base do tronco das árvores (35,93\%).

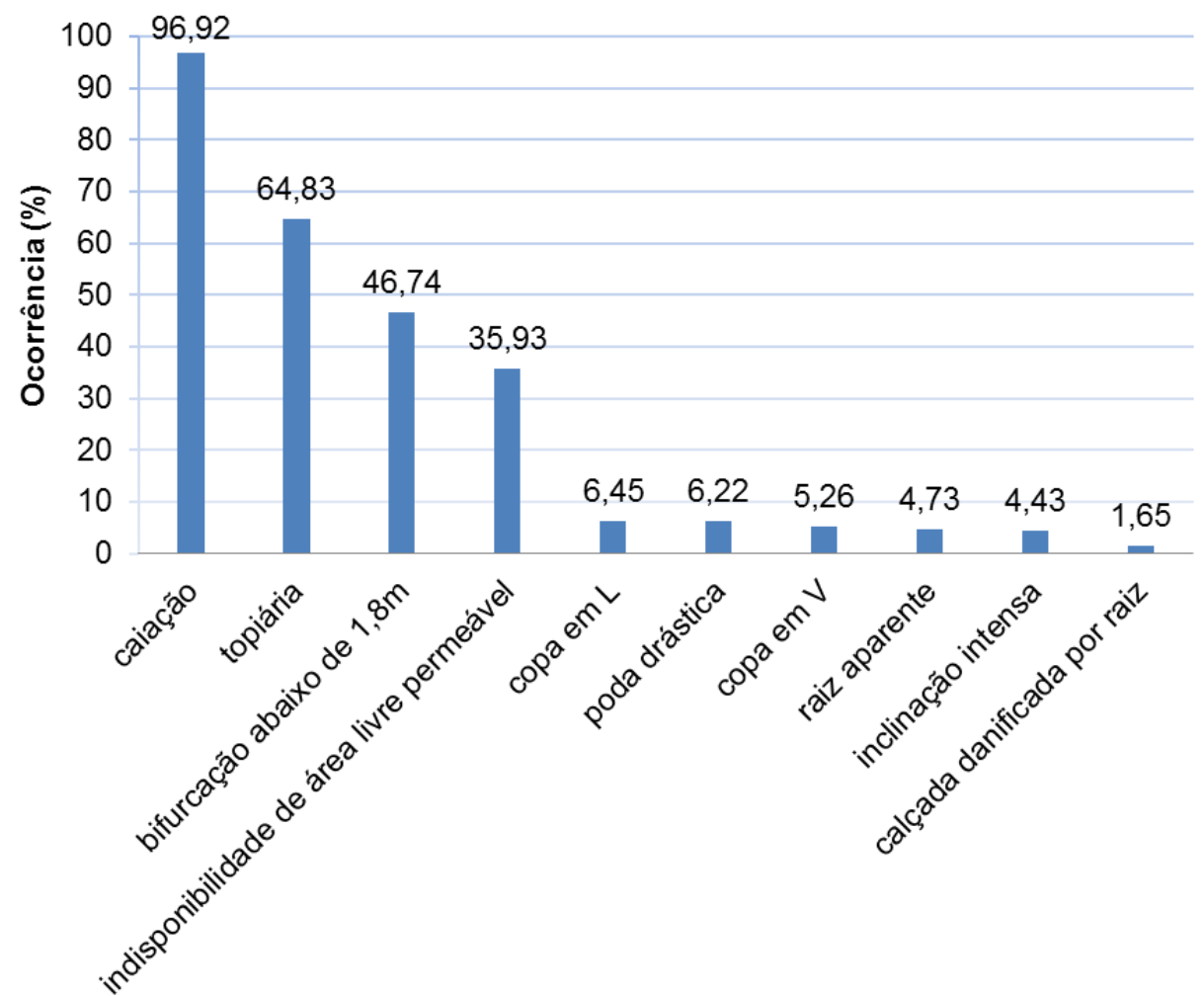

Figura 3. Diagrama de Pareto para os principais problemas encontrados na arborização urbana de Baraúna, RN

Figure 3. Pareto diagram for the main problems encountered in the urban afforestation of Baraúna, RN

A caiação (Figura 4a) é uma prática cultural arraigada no Brasil, que é erroneamente associada ao cuidado e proteção pela população em geral. Porém, a pintura dos troncos com cal ou tinta afeta a beleza individual de cada espécie, uma vez que todos os troncos passam a ser uniformizados, além de ser dispendiosa e desnecessária sob o ponto de vista de fitossanidade, pois as cascas das árvores apresentam mecanismos de defesas próprios (PIVETTA; SILVA FILHO, 2002).

A topiária é um tipo de poda estética que confere à copa das árvores formas geométricas (Figura 4b). É uma técnica muito utilizada em jardins do estilo francês, mas que podem causar grande estresse nas árvores por criar um desequilíbrio entre as proporções de copa e raiz do indivíduo. A taxa de ocorrência de $64,83 \%$ foi superior àquelas relatadas na 
literatura, em outras regiões do Brasil. Em Ourinhos, SP, 21,2\% das árvores podadas receberam poda topiária (SOUZA; DODONOV; CORTEZ, 2012).

A ocorrência com que observou-se a bifurcação do tronco abaixo de 1,8 m (Figura 4c) foi considerada alta, quando comparada a outras cidades. Por exemplo, Lima Neto e Biondi (2011) encontraram uma frequência de $18,8 \%$ para o mesmo problema no centro de Curitiba, PR. A alta percentagem no município potiguar também foi mais uma consequência negativa da prática de topiária em espécies exóticas, além de uma característica típica das espécies nativas do bioma caatinga. Recomenda-se o uso de espécies sem bifurcação abaixo de 1,8 $\mathrm{m}$ na arborização urbana para que o fluxo de pedestres não seja afetado, principalmente o trânsito de pessoas com deficiência ou mobilidade reduzida (LIMA NETO; BIONDI, 2011).

A área livre indisponível na base do tronco das árvores (Figura 4d) é um reflexo da reduzida área de canteiro. Este fato pode impedir a infiltração de quantidade suficiente de água e, como o solo é, muitas vezes compactado nestas áreas, ocorre frequentemente o encharcamento, principalmente sob chuvas intensas, o que estimula o afloramento de raízes em busca da água disponível (LIMA NETO; BIONDI, 2011). Apesar disto, a danificação de calçadas foi o problema de menor ocorrência no presente estudo. Contudo, é provável que o afloramento ainda venha a acontecer, principalmente no caso de Azadirachta indica e Ficus benjamina, que são espécies que apresentam crescimento radicular agressivo.
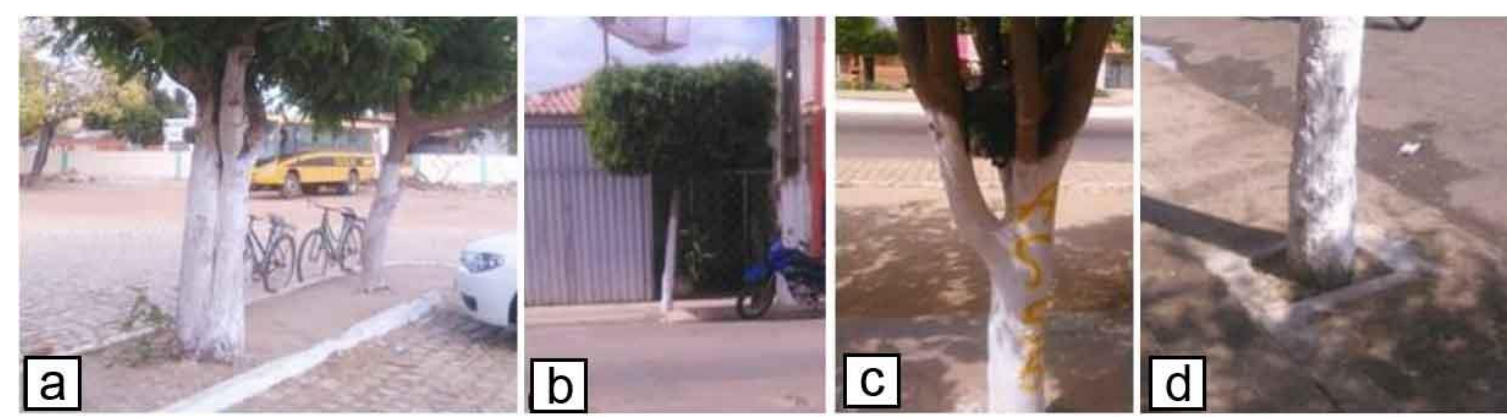

Figura 4. Problemas na arborização urbana de Baraúna, RN: a) caiação; b) poda topiária; c) bifurcação do tronco abaixo de $1,8 \mathrm{~m}$; e d) indisponibilidade de área livre na base do tronco das árvores

Figure 4. Problems in the urban afforestation of Baraúna, RN: a) whitewashing; B) topiary pruning; C) bifurcation below $1.8 \mathrm{~m}$; and d) unavailability of free area at the tree base

\section{CONCLUSÕES}

A arborização da avenida principal do município de Baraúna, RN, apresentou grande número de indivíduos. No entanto, considerou-se que a composição de espécies foi inadequada, devido ao emprego de elevado número de espécies exóticas ao bioma caatinga, apesar da grande diversidade de espécies nativas com potencial de aplicação em ambiente urbano. A utilização de espécies da caatinga é primordial, pois, além de já estarem adaptadas 
ao clima e, portanto, necessitarem de menor dispêndio com irrigação artificial, esta prática proporciona a valorização da biodiversidade local.

Os principais problemas encontrados na condução da arborização foram de caráter cultural. Tanto a prática de caiação quanto a poda de topiária, que foram largamente utilizadas na área de estudo, são ações desnecessárias do ponto de vista técnico e demonstraram uma preferência estética da população local. Recomenda-se a realização de um trabalho de educação ambiental com a comunidade para divulgação dos prejuízos que estas práticas podem causar ao desenvolvimento dos indivíduos.

\section{REFERÊNCIAS}

ALVAREZ, I. A.; KIILL, L. H. P. Arborização, floricultura e paisagismo com plantas da Caatinga. Informativo ABRATES, Londrina, v. 24, n. 3, p. 63-67. 2014.

BARROS, E, F. S.; GUILHERME, F. A. G.; CARVALHO, R. dos S. Arborização urbana em quadras de diferentes padrões construtivos na cidade de Jataí. Revista Árvore, Viçosa, v.34, n.2, p.287-295, 2010.

BURLE MARX, R. Considerações sobre arte brasileira. In: TABACOW, J. (Org.) Roberto Burle Marx: arte e paisagem. São Paulo: Nobel, 1987. p.69-76

CAICHE, D. T.; SILVA, S. R. M.; VIANA, S. M.; SILVA, R. S. da. Análise da supressão da arborização viária na cidade de São Carlos/SP no período de 2004 a 2013 Revista da Sociedade Brasileira de Arborização Urbana, Piracicaba, v.11, n.3, p. 93-103, 2016.

CALIXTO JÚNIOR, J. T.; SANTANA, G. M.; LIRA FILHO, J. A. Análise quantitativa da arborização urbana de Lavras da Mangabeira, CE, Nordeste do Brasil. Revista da Sociedade Brasileira de Arborização Urbana, Piracicaba, v.4, n.3, p.99-109, 2009.

HOPPEN, M. I.; DIVENSI, H. F.; RIBEIRO, R. F.; CAXAMBÚ, M. G. Espécies exóticas na arborização de vias públicas no município de Farol, PR, Brasil. Revista da Sociedade Brasileira de Arborização Urbana, Piracicaba, v.9, n.3, p 173-186, 2014.

INSTITUTO BRASILEIRO DE GEOGRAFIA E ESTATÍSTICA (IBGE). Cidades. Disponível em: $<$ http://cod.ibge.gov.br/38S>. Acesso em: 21 nov. 2016.

LIMA NETO, E. M.; BIONDI, D.;. Acessibilidade: um novo desafio para a arborização de ruas. In: BIONDI, D.; LIMA NETO, E. M.. (Orgs.). Pesquisa em arborização de ruas. Curitiba: Daniela Biondi, 2011, v. 1. p. 131-150.

LUCENA, J. N. de; SOUTO, P. C.; CAMAÑO, J. D. Z.; SOUTO, J. S.; SOUTO, L. S. Arborização em canteiros centrais na cidade de Patos, Paraíba. Revista Verde de Agroecologia e desenvolvimento sustentável, Pombal, v. 10, n. 4, p. 20 - 26, 2015.

MEDEIROS, J. A. Uso da craibeira (Tabebuia aurea \{manso\} benth. \& Hook.) na arborização urbana da cidade de São José do Seridó. Revista Eletrônica em Gestão, Educação e Tecnologia Ambiental, Santa Maria, v. 15, n. 15, p. 2935-2944, 2013. 
MELO, E. F. R. Q.; ROMANINI, A. Praça Ernesto Tochetto: importância da sua preservação histórica e aspectos de sua arborização. Revista da Sociedade Brasileira de Arborização Urbana, Piracicaba, v.3, n.1, p.54-72, 2008.

MICHALKA JR., C.; MALAGUTI, R. Intervenções no meio ambiente natural para construção das cidades. Revista Nacional de Gerenciamento de Cidades, Tupã, v.3, n.16, p. 122-137, 2015.

MORAES, L. A.; MACHADO, R. R. B. A arborização urbana do município de Timon/MA: inventário, diversidade e diagnóstico quali-quantativo. Revista da Sociedade Brasileira de Arborização Urbana, Piracicaba, v.9, n.4, p.80-98, 2014.

MORO, M. F.; WESTERKAMP, C. The alien street trees of Fortaleza (NE Brazil): qualitative observations and the inventory of two districts. Ciência Florestal, Santa Maria, v. 21, n. 4, p.789-798, 2011.

OliVEIRA, A. F. de; PEREIRA, J. A. A.; PEREIRA, G.de A.; COELHO S. J.; NEVES, C. L. P.; REZENDE, S. W.; GARCIA, F. H. S. Modalidades de poda avaliadas na arborização viária sob rede elétrica no Estado de Minas Gerais Revista da Sociedade Brasileira de Arborização Urbana, Piracicaba, v.10, n.2, p. 1-13, 2015.

PAULA, E. S.; SILVA, J. M.; MENEZES, P. C.; CARNEIRO, A. R. S.; MELO, V. L. M. O. A paisagem da caatinga: um gesto de Burle Marx na praça Euclides da Cunha. Paisagem Ambiente: Ensaios, São Paulo, n. 29, p.9-24, 2011.

PIVETTA, K. F. L.; SILVA FILHO, D. F. Arborização urbana. Jaboticabal: UNESP, 2002. 69p.

REDIN, C. G.; VOGEL C.; TROJAHN, C. D. P; GRACIOLI, C. R; LONGHI, S. J. Análise da arborização urbana em cinco praças do município de Cachoeira do Sul, RS. Revista da Sociedade Brasileira de Arborização Urbana, Piracicaba, v. 5, n.3, p.149-164, 2010.

SANTOS, T. O. B. dos; LISBOA, C. M. C. A.; CARVALHO, F. G. de. Análise da arborização viária do bairro de Petrópolis, Natal, RN: uma abordagem para diagnóstico e planejamento da flora urbana. Revista da Sociedade Brasileira de Arborização Urbana, Piracicaba, v.7, n.4, p.90-106, 2012.

SHASHUA-BAR, L.; HOFFMAN, M. E. vegetation as a climatic component in the design of an urban street: an empirical model for predicting the cooling effect of urban green areas with trees. Energy and Buildings, Amsterdã, v. 31, p. 221-235, 2000.

SILVA, R. N. Caracterização e análise quali-quantitativa da arborização em praças da área central da cidade de Arapiraca, AL. Revista da Sociedade Brasileira de Arborização Urbana, Piracicaba, v.7, n.2, p.102-115, 2012.

SIMPSON, J. R. Urban forest impacts on regional cooling and heating energy use: Sacramento county case study. Journal of Arboriculture, Campaign, v. 24, n. 4, p.201-214, 1998.

SOUZA, C. S.; DODONOV, P.; CORTEZ, R. B. Diversidade, fitossanidade e adequação da arborização ao ambiente urbano em um bairro na cidade de Ourinhos, SP, Brasil. Revista da Sociedade Brasileira de Arborização Urbana, Piracicaba, v.7, n.4, p.77-89, 2012. 